\title{
Ciberfeminismo. \\ Viejas luchas, nuevas estrategias: el escrache virtual como herramienta de acción y resistencia*
}

\author{
Paola Bonavitta* \\ Clara Presman ${ }^{* * *}$ \\ Jeli Camacho Becerra**** \\ Recibido: 2019-07-23 • Enviado a pares: 2019-07-30 \\ Aprobado por pares: 2019-08-28 • Aceptado: 2019-09-20 \\ https://doi.org/10.22395/angr.v18n36a9
}

\begin{abstract}
Resumen
En la Era de la Información se produjo una transformación total en cada plano de existencia, tanto en términos individuales como colectivos. En medio de estos cambios feroces, se modificaron las maneras de vincularnos en las redes y de ser-existir en los espacios virtuales de encuentros y desencuentros.

En este trabajo nos propusimos indagar acerca de las estrategias que recrean las mujeres y sexualidades no hegemónicas con las posibilidades que proponen las nuevas tecnologías para hacer frente a situaciones de violencia de género. De esta manera arribamos a los escraches virtuales ${ }^{1}$ como una herramienta de gran potencial. Analizamos los escraches virtuales a partir de un estudio de caso en Córdoba, Argentina con la intención de profundizar en los sentidos que adquieren los escraches y sus posibles efectos.
\end{abstract}

Palabras clave: escraches; feminismos; violencia de género; nuevas tecnologías; internet; mujeres; política.

- Artículo resultado de la investigación Comunicación Política en América Latina, registrado ante la Vicerrectoría de Investigación y Estudios de Posgrado, 2018, perteneciente al Cuerpo Académico Consolidado de Comunicación Política de la Benemérita Universidad Autónoma de Puebla, México.

* Doctora en Estudios Sociales en América Latina, Universidad Nacional de Córdoba, Argentina. Docente universitaria e investigadora del Conicet, Universidad Nacional de Córdoba, Argentina. Correo electrónico: paola.bonavitta@gmail.com. Orcid: https://orcid.org/0000-0003-4758-4202

.". Magíster en Derechos Humanos, Interculturalidad y Desarrollo, Universidad Nacional de Córdoba, Argentina. Docente y experta en gestión de proyectos sociales y ejecución de programas en territorio, implementación de planes de comunicación estratégica, Universidad Nacional de Córdoba, Argentina. Correo electrónico: clarapresman@unc.edu.ar. Orcid: https:// orcid.org/0000-0001-5727-4633

.... Magister en metodología de la Ciencia, Instituto Politécnico Nacional, México. Coordinadora de Encuentros Internacionales de Estadística de Género realizados por la división de asuntos de género de la Cepal. Trabajo en el área de Feminismos, Géneros y Sexualidades en FemGeS, México. Correo electrónico: jeli.camacho@gmail.com

1 La idea que sustenta el escrache es señalar y/o apuntar a algo o a alguien. Los escraches son conductas no convencionales, actuaciones o mecanismos que no están dentro de unos canales establecidos. 


\title{
Cyberfeminism. Old Struggles, New Strategies: The Virtual Escrache as a Tool of Action and Resistance
}

\begin{abstract}
In the Information Age there has been a total transformation in each plane of existence in both individual and collective terms. In the midst of these fierce changes, the ways of linking in networks and of being-existing in virtual spaces of encounters and disagreements have changed.

In this work we set out to inquire about the strategies that women and non-hegemonic sexualities recreate, making use of the possibilities proposed by new technologies, to deal with situations of gender violence. That is how we approached virtual escraches as tools of great potential. We analyze virtual escraches from a case study in Córdoba, Argentina to delve in the senses acquired by escraches and their possible effects.
\end{abstract}

Keywords: escraches; feminisms; gender violence; new technologies; internet; women; politics.

\section{Ciberfeminismo. Velhas lutas, novas estratégias: o escracho virtual como ferramenta de ação e resistência}

\begin{abstract}
Resumo
Na era da informação, é produzida uma transformação total em cada plano de existência, tanto em termos individuais quanto em coletivos. Em meio dessas mudanças, são modificadas as maneiras de relacionarmos nas redes e de ser-existir nos espaços virtuais de encontros e desencontros. Neste trabalho, propomo-nos a indagar sobre as estratégias que recriam as mulheres e as sexualidades não hegemônicas com as possibilidades que as novas tecnologias apresentam para enfrentar situações de violência de gênero. Dessa maneira, chegamos aos "escrachos virtuais" como uma ferramenta de grande potencial. Analisamonos a partir de um estudo de caso em Córdoba, Argentina, com a intenção de aprofundar nos sentidos que as desmoralizações e seus possíveis efeitos adquirem.

Palavras-chaves: escraches; feminismos; violência de gênero; novas tecnologias; internet; mulheres; política.
\end{abstract}




\section{Introducción}

En plena Era de la Información (Castells, 1996; 2001; Castel, 1995), los discursos sobre la relación de las mujeres y de las sexualidades no hegemónicas con las nuevas tecnologías se polarizaron entre las visiones optimistas y las pesimistas, estas últimas sostienen que la tecnología reforzaría dichas diferencias. En medio, existen reflexiones que valoran el potencial de las Tecnologías de la Información y la Comunicación (TIC), pero que a su vez llaman la atención sobre sus peligros y contradicciones.

En este escenario, el patriarcado con su gobernanza tecnológica continúa vigente como una de las estructuras de dominación más fuertes y se presentan fenómenos como el ciberacoso y apuestas teóricas como el ciberfeminismo que es necesario tener presentes y reflexionar sobre ellos en este marco patriarcal y sexista.

Las TIC permiten acceder y ubicar a los usuarios ${ }^{1}$ como productores de información. Estas permiten crear canales de comunicación multidireccionales, así como territorios de construcción de subjetividades, narrativas y representaciones del mundo. Las TIC se posicionan de este modo como una dimensión informativa, comunicativa y representativa al mismo tiempo que cuentan con grandes potencialidades.

Pareciera a simple vista que las implicaciones sobre los usos y accesos a internet quedan resueltas con la supuesta Sociedad de la Información y que el sueño de la democratización de la información es un hecho en el siglo XXI. Sin embargo, Castells señala que:

[...] se trata de una sociedad en la que las condiciones de generación de conocimiento y procesamiento de información están siendo sustancialmente mejoradas por una revolución tecnológica centrada en el procesamiento de información, la generación del conocimiento, y las tecnologías de la información. (p.7)

En medio de estos cambios feroces existen, por un lado, miradas con un claro sesgo positivo hacia las nuevas tecnologías y por el otro, perspectivas que se pesimistas frente a estos avances tecnológicos. Tal como propone Postman (1991), hay miradas tecnofílicas que sostienen que la tecnología es una amiga, que hace que la vida sea más larga, mejor y más feliz. Esta perspectiva exalta las dimensiones positivas de la tecnología, bajo el entendido de que la innovación tecnológica es siempre sinónimo de desarrollo, progreso y felicidad. Diametralmente opuesta, existe una mirada tecnofóbica desde la cual se percibe a la tecnología como destructora de la vida social y responsable de crear una cultura sin fundamentación moral.

Si bien la revista Anagramas acoge las normas de la Real Academia Española de la Lengua al momento de escribir plurales mediante el genérico masculino, resulta primordial hacer énfasis en que dicha normativa para el plural pareciese borrar e invisibilizar lo femenino. A lo largo del presente artículo el uso del plural siempre incluye masculino y femenino. Al decir usuarios se hace referencia a usuarios y usuarias, al decir productores se hace referencia a productores y productoras, etc. (Nota del ed). 
Del mismo modo, los discursos sobre la relación de las mujeres y las sexualidades no hegemónicas con las nuevas tecnologías se han polarizado entre visiones optimistas, que proponen que la tecnología ayudaría a diluir las diferencias asociadas al género y visiones pesimistas que sostienen que la tecnología reforzaría dichas diferencias y desigualdades.

\section{Peligros en la red}

Hannah Arendt adujo que el mundo de las máquinas se transformó en sustituto del mundo real (Arendt, 1993). El tecnologicismo y los medios serían entonces una ideología totalitaria y las redes virtuales una parte central de esa maquinaria que todo lo observa, que todo lo abarca y que se encarga de reproducir los ideales de un grupo que programa y dirige la vida de la amplia mayoría. Nada queda por fuera del ojo voyerista. Nadie escapa al control social (Bonavitta y de Garay, 2014).

En ese contexto, entre los nuevos peligros existentes surgen las brechas digitales de género, el acceso desigual y las violencias de género que aparecen en el acceso, uso y apropiación de las TIC. Y esto se da así puesto que el patriarcado continúa existiendo como una de las estructuras de dominación más fuertes que sostiene fenómenos como el ciberacoso. En contrapartida, también nacen propuestas teóricas que habilitan las nuevas tecnologías y la conectividad en red, tales como el ciberfeminismo y una serie de prácticas y estrategias no hegemónicas organizadas por mujeres para hacerle frente a las violencias y desigualdades en el ámbito virtual.

Según Nuria Verges Bosch (2017), el ciberacoso es un ataque realizado a través de un medio virtual, dirigido a una persona física. Estos ataques se pueden enfocar en insultar, avergonzar, calumniar, desprestigiar, silenciar, censurar y chantajear o extorsionar, así como también se pueden basar en procesos sociales y herramientas tecnológicas más o menos sofisticados. Pero el ciberacoso no solo se limita a una acción agresiva realizada en un momento determinado, Jeong (2015) propone que el ciberacoso tiene dos caras importantes a analizar. Una que se define por el comportamiento concreto realizado por quien efectúa la agresión y otra que se refiere al contenido y los efectos de esa acción. En este sentido, la autora explica que si miramos el acoso solo como contenido, nos fijamos en las "amenazas de muerte" en un extremo del espectro y "mensajes molestos" en el otro extremo.

De esta manera, el debate termina por girar en torno a los derechos civiles frente a la libertad de expresión y resulta complejo delimitar cuándo se cruza el límite: ¿Dónde está la línea entre los comentarios molestos y el peligro inminente, o entre los chistes y las amenazas? Esta reflexión nos lleva a pensar al acoso cibernético y las violencias de género dentro de un marco analítico que valora los comportamientos, impactos y consecuencias que estos conllevan. De acuerdo con este planteamiento 
resulta importante pensar las diferencias que pueden tener el ciberacoso según quién lo perpetra, quién lo sufre y en qué contexto social, cultural, económico y político tienen lugar.

Una apuesta teórica que alberga el auge de las nuevas tecnologías es la corriente ciberfeminista. Esta surge a principios de la década de 1990 a raíz de un documento elaborado por Donna Haraway en Estados Unidos, denominado Manifiesto Cyborg. Almudena García Manso (2007) explica que el Manifiesto Cyborg de Haraway representa la búsqueda de un nuevo feminismo socialista capaz de luchar contra lo que denomina la informática de la dominación, un nuevo espacio creado por la tecnología ambivalente, fluida y contradictoria, en la cual se pierde la referencia y la identidad. La llamada informática de la dominación (masculina) no afecta a todos por igual.

En este marco, las mujeres y las disidencias, como parte de los grupos desprotegidos, se ven particularmente afectadas puesto que las nuevas tecnologías han creado una informática de la dominación que penetra en las diversas áreas de la vida. Según Haraway, nos debemos alejar de toda tecnofobia y aceptar la unión cuerpo-máquina como una extensión del cuerpo, de nuestras vidas e intimidad. El ciberfeminismo piensa que solo así podremos desterrar la sumisión dominativa de la informática (García Manso, 2007).

Desde sus comienzos hasta hoy, existen diferentes definiciones del ciberfeminismo. Algunas proponen que se trata de una apuesta teórica y política, otras proponen que no hay una definición certera del mismo. Lo que está claro es que el ciberespacio no está libre de contaminación, no es un espacio neutro, existe una clara dominación masculina. Por esto, la escritora paraguaya Faith Wilding (1998) explica:

Es necesario ampliar al máximo el horizonte del ciberfeminismo: el territorio del ciberfeminismo es amplio. Incluye el espacio objetivo del ciberespacio, instituciones de diseño industrial e instituciones de educación -territorios en los que el proceso tecnológico es clasificado generizadamente [sic] de una forma que excluye a la mujer el acceso a los puntos de poder de la tecno cultura. (Wilding, 1998, p. 18)

Con el auge de las redes sociales, el ciberfeminismo se consolidó con mayor fuerza. Por un lado, las redes sociales otorgaron visibilidad a los discursos de las mujeres, mayor participación en la vida pública y la posibilidad de encuentros y articulaciones de grupos, sectores y movimientos feministas. Sin embargo, ello no derivó en una igualdad de acceso, participación, producción ni respeto a los derechos humanos de mujeres y niñas.

Las redes digitales son un espacio más en el cual el sistema patriarcal ejerce mecanismos de poder. Aunque es cierto que las mujeres aprovechan cada vez más las TIC en su vida cotidiana, también es verdad que se produce "una brecha digital 
de género" que no solo se manifiesta en menor número de mujeres usuarias, sino también en la persistencia de desigualdades estructurales específicas de género que constituyen barreras para su acceso y uso. Se supone que el acceso a internet es libre y democrático. Ahora bien: ¿quiénes pueden acceder a las redes? ¿Quiénes se convierten en usuarias activas y permanentes en los espacios virtuales? ¿Para quién es la accesibilidad? Así, no es lo mismo el acceso al espacio virtual de una mujer de clase media urbana que aquel de una mujer rural y pobre. Es por ello que se vuelve necesario observar desde una perspectiva interseccional los cruces existentes en relación con la accesibilidad real de las mujeres.

Por su parte, Nuria Verges Bosch (2017) sostiene que aún las mujeres representan una minoría entre las estudiantes y trabajadoras cualificadas en el sector de las TIC:

[...] hemos podido ver anteriormente c[ó|mo las plataformas comerciales replican las estructuras de poder y discriminación que existen en nuestras sociedades patriarcales. Y, finalmente, otro claro indicio de desigualdad de género en el ámbito digital, consiste en ver que las personas que deciden acerca de la gobernanza de estas plataformas y obtienen los mayores beneficios económicos de las redes sociales son hombres blancos y occidentales, como Zuckerberg (Facebook), Dorsey (Twitter), Brin y Page (Google), Gates (Microsoft), entre otros. (Verges Bosch, 2017, p. 24)

Frente a este contexto, si bien, el uso de las redes ha permitido tomar la palabra y generar espacios de diálogo y encuentro, puesto que las mujeres han logrado formar grupos, colectivos, organizaciones que circulan digitalmente y que no solo vociferan sino que también repercuten en acciones concretas que pueden ser visibles en los movimientos sociales en América Latina, es verdad que las brechas digitales de género continúan vigentes. Lo anterior se debe a que el ciberespacio todavía se presenta como un escenario más de factores micro políticos de desigualdad de género (aunque también de desigualdad de clase, raza, etnia, nacionalidad, etcétera) que actúa como una extensión del uso desigual de otros recursos por parte de las mujeres. La ciencia y la tecnología, la economía del conocimiento, así como el diseño y el uso de los medios de comunicación siguen siendo de dominio principalmente masculino.

No obstante, se nos ha dicho y publicitado que la sociedad digital es democrática, igualitaria y universal. Pero, ¿̇realmente es así? ¿Cómo hablamos de igualdad si no todos tienen el mismo acceso ni las mismas posibilidades de disponer de estas herramientas? La conectividad no está distribuida de manera igualitaria, tampoco los recursos, el acceso y las capacidades de apropiación de los aparatos o el sistema, mucho menos, las posiciones de poder entre quienes poseen, organizan, diseñan y ejecutan las nuevas tecnologías.

Además, como en todas las demás áreas de la vida, las mujeres están en condi- 
ciones desiguales de acceso, uso y gestión. Como hemos expresado anteriormente, frente a esta realidad, diferentes teóricos se inscriben a dos posturas contrapuestas: los optimistas de la sociedad de la información que sostienen que la tecnología ayudaría a diluir las diferencias asociadas al género y los pesimistas que aseguran que la tecnología reforzaría las brechas de género puesto que esta nueva sociedad no deja de estar gobernada por un sistema superior que la engloba: el patriarcado. Tal es así que, en los últimos años, las redes sociales se convirtieron en el principal receptor de denuncias de mujeres que sufrieron distintos tipos de violencia machista. Estos nuevos discursos fueron denominados escraches y cuentan con una retórica propia e innovadora. Tal como señala Verges Bosch:

La mayoría de violencias on-line [en línea] las sufren las mujeres y buena parte de ellas son violencias de género. Lxs [sic] participantes en chats y juegos con nicks [sic] en femenino reciben más mensajes amenazadores y con contenido sexual. La mayoría de agresores son hombres y gran parte de éstos [sic] son conocidos por estas mujeres, mayormente se trata de sus parejas o exparejas. Finalmente, anotar que las personas del colectivo LGTBIO también resultan fuertemente agredidas por las violencias on-line [en línea] basadas en género, tres veces más que las personas heterosexuales. (Verges Bosch, 2017, p. 44)

En Argentina, la práctica del escrache tuvo mayor visibilidad en los años posteriores a la dictadura militar, en la década de 1970, pero recientemente se convirtió en una herramienta que las feministas emplean con ahínco como acción positiva de resistencia. En Latinoamérica el escrache es una práctica conocida y utilizada, basada en la acción directa de colectivos organizados ante la falta de acción de otras instituciones. Puntualmente, en Argentina la agrupación de Derechos Humanos Hijos (acrónimo de Hijos e Hijas por la Identidad y la Justicia contra el Olvido y el Silencio) popularizó dicha práctica bajo la consigna " si no hay justicia hay escrache", para visibilizar a los represores de la dictadura cívico militar que aún estaban libres ante la impunidad del poder político y judicial tras las leyes de indulto a los genocidas.

Los escraches surgen frente a la ineficacia de la policía y otras instituciones para resolver las múltiples violencias de género, acosos y hostigamientos que vivencian las mujeres y las personas LGTTBOI. "Como respuesta a la situación que se ha tornado cotidiana, las mujeres debemos decidir cuidarnos y protegernos a nosotras mismas. Crear nuestras propias estrategias de defensa y de ser posible, acompañarnos" (Sánchez Kuri, 2016).

Según Sánchez Kuri (2016), "le]l escrache es un juicio público abierto a la sociedad para que la opinión pública emita sus juicios sobre la situación, y de alguna manera, ayude a resolverlos a favor de las personas afectadas". Los escraches feministas surgieron en Argentina y después se extendieron a otros países de la región latinoa- 
mericana, como arma de lucha y resistencia ante la flagrante violación a los derechos de la humanidad, consecuencia de los gobiernos dictatoriales (Sánchez Kuri, 2016).

Para Alejandra Zani (2017), el surgimiento del escrache como herramienta de defensa ante la violencia machista y patriarcal

$[\ldots]$ es un punto fugaz en el cruce entre el avance de la lucha de las mujeres y el crecimiento de las redes sociales. Con todas las complejidades que estas dos transformaciones implicaron en la vida social, el escrache como uno de sus resultados habilitó la existencia de nuevas discursividades en un contexto de violencia aún irrestricta. El discurso del escrache no está jamás escrito en potencial ni se hace preguntas a sí mismo: es el producto de una urgencia. (Zani, 2017)

En algunos casos emblemáticos, los escraches comenzaron como denuncias públicas en las redes y finalizaron en causas penales, procesos judiciales e incluso, en procesamientos de los acusados, como fue el caso de Cristian Aldana (cantante de la banda El Otro Yo, acusado de abusar sexualmente a siete menores de edad) y José Miguel Del Pópolo (cantante del grupo La Ola que quería ser Chau, acusado por abuso sexual). Por tanto, dentro de los movimientos feministas se ha vuelto un recurso legítimo y valioso para poder sancionar socialmente a quienes ejercen violencias machistas, exponiendo los nombres y las situaciones concretas del ejercicio de dicha violencia patriarcal.

Como hemos expresado anteriormente, una de las grandes posibilidades que permite la virtualidad es la agrupación en redes de mujeres (como los grupos de madres, ecologistas, veganas, productoras, etcétera) y/o en redes feministas (de trabajo, discusión, pro-aborto, etcétera) que han posibilitado el acceso y la proximidad a otras mujeres con los mismos intereses o las mismas situaciones de vida y han fomentado encuentros y militancias virtuales que, en ocasiones, se convierten en acciones concretas fuera del ciberespacio. De hecho, ciberfeministas como Padilla y Mezquita (2006) o Zafra (2015), destacan que no solo se empieza a habitar, hacer y tejer sino y sobretodo, cabe la posibilidad de empezar a deshacer y destejer el género y la red también, desde afuera de las mismas redes. Es por eso que en este trabajo nos enfocamos en un caso particular de uno de estos espacios virtuales feministas que se construyen como territorios de reflexión, acción y disputas.

Para pensar acerca de un caso de ciberfeminismo, analizamos el grupo feminista que surgió en el 2017 en la red social Facebook con anclaje territorial en la ciudad de Córdoba, Argentina: Feministas Dialogando (mujeres, tortas y trans) -que en adelante se nombra como FD- y abordamos los escraches virtuales realizados desde esta plataforma. Este grupo de más de tres mil miembros excluye explícitamente de su participación a varones cisgénero. 


\section{Métodos y técnicas de análisis}

Para realizar este trabajo utilizamos la metodología cualitativa por considerarla una opción óptima para analizar subjetividades, representaciones sociales de género y discursos. Dentro de este método, implementamos dos técnicas: la entrevista focalizada y el análisis de contenido del discurso mediático.

Realizamos entrevistas focalizadas a las administradoras y creadoras del grupo cerrado de Facebook, Feministas Dialogando (FD), indagamos acerca de los escraches, su postura como administradoras frente a lo que se publica y lo que no, lo que se considera o no como escrache, etcétera.

En tanto que el análisis de contenido del discurso mediático se debe concebir, según Díaz y Navarro (1998), como un procedimiento destinado a desestabilizar la inteligibilidad inmediata de la superficie textual para mostrar aspectos que no son directamente intuibles y, sin embargo, que están presentes. La finalidad del análisis de contenido es identificar actitudes, creencias, deseos, valores, centros de interés, objetivos, metas de personas, grupos, organizaciones, países, etcétera. En los medios se construyen creencias y opiniones que se estructuran como reglas sociales (Vega Montiel, 2010).

Para comprender los discursos, es importante considerar no solo qué escriben, dicen o muestran, sino también cómo lo hacen, en otras palabras, tanto su contenido como su enunciación. Toda enunciación de un texto se concibe como un acto que tiende a modificar las relaciones entre el emisor y el receptor y el contexto que le rodea. Por ello, analizamos los escraches privados publicados en el grupo FD en Facebook sin dejar de lado las maneras de decir y también lo no dicho del discurso en cuestión. Siempre se resguarda la identidad de las denunciantes y el total anonimato de la información publicada.

Para realizar el trabajo seleccionamos un corpus compuesto por quinientos escraches realizados en el grupo FD desde su creación hasta ahora. Tomamos cada uno de los escraches y analizamos su contenido de acuerdo con lo que denunciaba, la manera en que lo denunciaba y las emociones que reflejaba cada escrache.

Cabe aclarar que los escraches no eran (ni son) visibles para cualquier usuario de Facebook, sino que exclusivamente para los miembros de la grupa (como sus miembros lo denominan).

\section{Estudio de un caso: Feministas Dialogando, Córdoba}

El grupo FD -que funciona en Facebook de manera cerrada y secreta- surgió en mayo del 2017 como un "grupo satélite" de la primera iniciativa, Feministas Trabajando, el 
cual se originó ante la fuerte situación de crisis económica acontecida en el país, con el fin de ser una bolsa de trabajo para mujeres. Luego del éxito y la gran cantidad de miembros del grupo, con el objetivo de no desviar la búsqueda y oferta laboral, se creó otro grupo que fuera un espacio orientado estrictamente al debate. Así surgió Feministas dialogando (mujeres, tortas, trans-), con el objetivo de ser un espacio para mujeres, lesbianas y transgéneros en el cual poder discutir, debatir y reflexionar sobre feminismos, literatura feminista y revisar temáticas particulares analizadas desde una perspectiva feminista. A su vez, se propuso como un espacio de contención, para casos de urgencia de violencia, acoso, o para acompañar en denuncias y/o abortos.

FD para enero de 2018 cuenta con 3.429 miembros, si bien no existen estadísticas ni información exacta acerca de las particularidades de sus integrantes, en una entrevista realizada a comienzos del 2018, las administradoras del grupo expresaron que se trata de una amplia mayoría de participantes universitarios y/o egresados universitarios de clase media.

A pesar de que en sus inicios la propuesta estaba vinculada al debate y a la circulación de información, rápidamente se comenzaron a efectuar escraches, casi en su totalidad a varones cis (excepto uno a un varón transgénero) por sostener actitudes violentas, machistas y misóginas hacia miembros del grupo.

La creciente cantidad de denuncias mediante los escraches de mujeres (son más de quinientos escraches realizados en la grupa desde su creación), evidenció un estado de situación en Córdoba que indicaba sobre todo una acción ineficiente por parte de la justicia ante este tipo de denuncias. Consecuentemente, adquirió gran peso el poder contar con el espacio virtual propiciado por FD para visibilizar y alertar acerca de estas situaciones. Ante esto, se generaron estrategias organizativas destinadas a preservar a las mujeres que denunciaran.

Así, las administradoras de FD propusieron dos alternativas de acción: 1) hacer el escrache de forma anónima mediante un enlace que redirige a un archivo compartido en la plataforma Google drive, desde allí llega la denuncia de manera anónima a las administradoras para que luego ellas las publiquen en el grupo; 2) realizarlo de manera personal directamente sobre el muro del grupo. Existe un registro de los escraches, alrededor de quinientos, en un álbum en el que está sistematizada toda la información bajo el nombre: "Base de datos machirulos / lugares violentos".

De este modo, se visibilizaron nombres y apellidos de hombres catalogados como "machitos violentos" o machirulos. Algunas publicaciones se realizaron con el fin de que el escrache se hiciera viral fuera del grupo y de este modo apelar a la condena social del varón violento, otras con el objetivo de que la denuncia permaneciera en los límites virtuales y privados del grupo cerrado FD para alertar a los integrantes del grupo de las actitudes de los sujetos denunciados. 
La idea de habilitar el espacio a los escraches en el grupo no apuntaba a que luego se continuara con acciones fuera del ámbito virtual. Sin embargo, hubo casos en los que a partir de denuncias recurrentes a un mismo sujeto, se llevó a cabo una denuncia con mayor peso en el Polo Integral de la Mujer en Situación de Violencia². Una de las administradoras del grupo remarcó la potencia de la práctica del escrache:

Ha habido momentos muy poderosos de encuentro a partir de los escraches. Los escraches entendidos como un espacio de encuentro, que genera red, que haga sentir a la otra que no están solo buscando contención, que nos estamos acompañando. (Comunicación personal, administradora del FD, mayo de 2018)

En el marco de FD, el escrache se utiliza como modo de comunicación sobre aquel que genera un riesgo para las demás mujeres. Es una acción de combate, pero también de sororidad, compañerismo. Muchas veces, la denunciante escracha de manera anónima (es decir, da el nombre del victimario, pero no el nombre de la víctima), otras veces se brinda la identidad de víctima y victimario. Quienes leen el mensaje, al mismo tiempo, revisan el perfil del machito violento y alertan a aquellas compañeras que tienen una amistad virtual en Facebook con el victimario. En este grupo, se habían realizado hasta agosto del 2018 más de quinientos escraches registrados por las administradoras. El escrache venía como una advertencia: "Tené cuidado, mi ex es psicólogo y es violento" (comunicación personal, administradora del FD, mayo de 2018)

En los últimos años las redes sociales comenzaron a ser el principal soporte para alojar denuncias de mujeres que sufrieron distintos tipos de violencia machista. Muchos de estos discursos se apropian de una retórica propia. Un fenómeno emergente, un proceso en construcción y en constante reformulación.

Desde su origen, el escrache es un discurso no hegemónico. Emerge de este modo porque no encuentra espacio en las estructuras institucionales para ser resuelto. Del análisis de los escraches realizados en FD podemos afirmar que estos se realizan a raíz de que muchas veces, las instituciones que se deberían encargar de canalizar estas denuncias relativizan las experiencias de las mujeres y hacen necesario recurrir a otros medios para acelerar los procesos y construir solidaridades y sobre todo sororidades. Más aún en el marco de una sociedad machista y patriarcal que, como dice Rita Segato (2008), expande sus violencias: "La violencia patriarcal, es decir, la violencia misógina y homofóbica de esta plena modernidad tardía -nuestra era de los derechos humanos y de la ONU- se revela precisamente como síntoma, al expandirse sin freno" (p. 17).

Es una dependencia del Gobierno de la Provincia de Córdoba al servicio de todas las mujeres y particularmente de las víctimas de violencia de género, con un abordaje interdisciplinario para brindar asistencia, acompañamiento y contención. Se recibe a la mujer en situación de violencia y, en caso de corresponder, se la acompaña y traslada a la Unidad Judicial para realizar la denuncia. 
A continuación analizamos algunas de las frases recurrentes que recogimos de entre los quinientos escraches realizados en el grupo FD. Para poder analizar mejor la información, agrupamos algunas frases por categorías:

\section{Categoría a) Dolor, vergüenza, temor}

"Lo hago para darles advertencia y sacarme un poquito de encima este peso horrible"; "Escribir esto no es nada fácil"; "Siento impotencia"; "Me muero del miedo"; "Les escribo porque necesito ayuda"; "Me es difícil hacer esto como a todas, pero luego de muchos procesos no solo decidí sino que juré decir la verdad, mi verdad, porque es lo mínimo que me debo a mí misma"; "Este es hoy mi deseo, ponerle palabras al dolor"; "muches [sic] no nos animamos a completar con nombres por miedo a que se filtre información" (extractos de escraches publicados en el grupo FD).

En las situaciones de violencia machista quien suele sentir la culpa de lo sucedido es la víctima y no el victimario. En una sociedad patriarcal en la que nos han enseñado que las mujeres y sus cuerpos no valen nada y son mercancía puesta para el uso del otro (siempre varón), no debe sorprender que sean las mujeres quienes sientan que se comportaron mal. La sociedad, de hecho, frente a una violación suele decir: "pero mira cómo iba vestida" o "andaba sola de noche".

En una estructura social patriarcal, las violaciones y los violadores son menos castigados que las víctimas que usaban escote o minifalda. No obstante, como señala Rita Segato (2008):

Uso y abuso del cuerpo del otro sin que este participe con intención o voluntad, la violación se dirige al aniquilamiento de la voluntad de la víctima, cuya reducción es justamente significada por la pérdida de control sobre el comportamiento de su cuerpo y el agenciamiento del mismo por la voluntad del agresor. La víctima es expropiada del control sobre su espacio-cuerpo. (p. 38)

En esos abusos patriarcales que describe Segato, lo que queda en el cuerpo de las mujeres son las huellas de un dolor desgarrador, la marca del terror y de la expropiación machista de su propio territorio. En los escraches, el dolor y la vergüenza se presentan permanentemente y constituyen una de las principales dificultades para hablar abiertamente al respecto en una sociedad que revictimiza y que desconfía siempre de la víctima: "Eres inocente hasta que se demuestre lo contrario" (ONU, 2018) y mientras tanto, las víctimas atraviesan los dolores en soledad, con una sensación de desgarro interior. El poder expresar en la grupa lo que sucedió, les libera y les permite transmutar ese dolor. 


\section{Categoría b) Machismo reiterado}

"Sé que no soy la única denunciante"; "Decido compartirles esto que escribí para sumar a los relatos de los compas [sic] que están escrachando a este tipo"; "Si vivieron situaciones de violencia de cualquier tipo con esta persona, expónganlo por favor"; "Hablemos sin miedo, sé que a varias les pasó con él"; "No soy la única denunciante y las otras mujeres de mi familia todavía no están preparadas para hacerlo público"; "Este tipo me agarró de los pelos y me reventó la cabeza contra una columna de hierro" (extractos de escraches publicados en el grupo FD).

Las mujeres denuncian una y otra vez las violencias machistas, pero la justicia es patriarcal. El caso de Micaela García ${ }^{3}$ en Argentina o de María Da Penha ${ }^{4}$ en Brasil dan muestra de una permanente mirada benévola sobre los victimarios y no sobre las víctimas mujeres; los cuerpos de las mujeres no tienen valor, la justicia no brega por ellos.

Rita Segato (2008, p. 38) sostiene que los actos violentos sobre los cuerpos de las mujeres, las violaciones específicamente -aunque podemos extenderlo a otras violencias machistas-, están vinculados a la consumición del otro, a un canibalismo tal que, para que la otra persona exista, debe ser "incluida" en el cuerpo de quien le ha devorado. La víctima existe solo como parte del proyecto del dominador. Se genera allí un acto de dominación física y moral (Segato, 2008, p. 38) que alimenta el poder que siente el victimario, y es por eso que una y otra vez se repiten las violencias, para anular y desarmar a las víctimas.

Si al abrigo del espacio doméstico el hombre abusa de las mujeres que se encuentran bajo su dependencia porque puede hacerlo, es decir, porque estas ya forman parte del territorio que controla, el agresor que se apropia del cuerpo

\footnotetext{
La joven de ventiún años era una activa participante del \#Niunamenos, contra la violencia de género y en pro de los derechos de las mujeres. Era oriunda de Concepción, Uruguay, pero vivía en Gualeguay, donde cursaba un profesorado universitario en Educación Física. La joven desapareció el $1^{\circ}$ de abril de 2017 y una semana después encontraron su cuerpo debajo de un árbol, en un campo denominado Seis Robles, a 2,5 kilómetros de la Ruta 12. Lo halló un equipo policial que formó parte del operativo de más de doscientos efectivos que se dedicó durante toda la semana al rastrillaje de las zonas de campo. El femicida fue Sebastián Wagner, quien confesó haber violado a la joven. Lo condenaron a cadena perpetua, también se apresó a Néstor Pavón, quien se declaró inocente y dijo que lo único que hizo fue prestarle el auto a Wagner, pero que según Wagner, también violó y fue quien ahorcó a Micaela García. Wagner debía haber estado preso en ese momento pues cumplía condena por otras dos violaciones. Cumplió seis de sus nueve años y fue liberado por el juez de ejecución de Entre Ríos, Carlos Rossi, quien le otorgó el beneficio de la libertad condicional a pesar de que había dictámenes que lo desaconsejaban taxativamente. Había múltiples pericias que sostenían que Wagner no podía estar en libertad.

4 Maria da Penha Maia Fernandes (Fortaleza, 1948) es una biofarmacéutica brasileña víctima de violencia doméstica que ha estado luchando para visibilizar a los agresores y condenarlos. En 1983, su ex-marido, el economista y profesor universitario colombiano Marco Antonio Heredia Viveros, intentó matarla en dos ocasiones. La primera vez le disparó con un arma de fuego mientras ella dormía y simulando un asalto le causó una paraplejia irreversible; en la segunda intentó electrocutarla. Como resultado, Penha sufre de paraplejía. Nueve años después, su agresor fue condenado a ocho años de prisión, salió en 2002 mediante recursos jurídicos, después de tan solo dos años de privación de libertad. El caso llegó a la Comisión Interamericana de Derechos Humanos de la Organización de Estados Americanos (OEA) y se le consideró, por primera vez en la historia, un crimen de violencia doméstica.
} 
femenino en un espacio abierto, público, lo hace porque debe hacerlo para demostrar que puede. En un caso, se trata de una constatación de un dominio ya existente; en el otro, de una exhibición de capacidad de dominio que debe ser reeditada con cierta regularidad y puede ser asociada a los gestos rituales de renovación de los votos de virilidad. El poder está, aquí, condicionado a una muestra pública dramatizada a menudo en un acto predatorio del cuerpo femenino. (Segato, 2008, p. 45)

Las relaciones desiguales de poder -siempre presentes- establecen los límites en un yo-macho y una otra desprovista de poder, de defensa, incluso de autonomía. Las mujeres, hartas de este comportamiento machista repetitivo y permanente, deciden escrachar para alertar a las demás pero también para hallar a otras que hayan sido víctimas del abusador y crear sororidad.

\section{Categoría c). Sororidad}

"Necesito Compartirlo para cuidarnos"; "No lo difundan fuera de la grupa [sic]. Solo quiero advertirles a ustedes"; "Lo cuento ya no por mí sino para que no le pase a nadie más que te rodee."; "Ante la violencia machista, escrache feminista"; "Tengo una deuda conmigo misma y con todas ustedes"; "Estén alertas con sus amigas, hermanas y vecinas" (extractos de escraches publicados en el grupo FD).

Los machistas violentos, como señala Segato (2008), se comportan como productores y reproductores de impunidad (p. 43). Actúan inescrupulosamente con la certeza de que nada les sucederá. Una de las principales funciones del escrache es alertar a otras compañeras para protegerlas. Se dan datos del varón: su edad, círculos, profesión, etcétera. Se reconoce en qué lugares frecuenta y porqué es de temer. Esto se hace sobre todo en aquellos varones con perfiles más altos (músicos, militantes, etcéteras) que circulan en diferentes ámbitos y son muy populares.

La sororidad manifiesta el compromiso que se presenta con la otra y se exalta como muestra del orgullo feminista.

\section{Categoría d). Machismo en la militancia progresista}

"Violento, abusivo y golpeador que va a marchas y milita en organización social"; "Quiero advertir a todes [sic] en la grupa [sic] de este waso [sic] que es un psicópata"; "Se aprovecha de su condición de amigo/ compañero de militancia"; "Hay que votar en la Facultad y ambas listas tienen entre sus representantes a machirulos denunciados por abusos" (extractos de escraches publicados en el grupo FD).

Reivindicamos el escrache como herramienta política que históricamente hemos usado para denunciar la violencia machista, para poder hacer público e identificar los violentos que estratégicamente reproducen un discurso "pro- 
gresista", levantando banderas del feminismo y la lucha contra la violencia hacia las mujeres como un mecanismo más de perversión y de manipulación para empatizar con compañeras dentro de los círculos militantes. (extracto de escrache publicados en el grupo FD)

Existen espacios que se suponen más solidarios que otros. En el imaginario social la militancia pareciera ser un lugar de mayor encuentro y comprensión. No obstante, allí también se reproducen desigualdades de género, abusos de poder por razones de género, exclusiones, desinterés por cuestiones de género, sexismos, machismos, microviolencias y hasta abusos explícitos. Es por ello que se hace especial referencia a estos espacios porque se espera que sean lugares de luchas comunes con personas deconstruídas que dejen de reproducir estereotipos sexistas, microviolencias o microsexismos.

En esta categoría se denuncia a los compañeros militantes que aprovechan su rol para ejercer abusos de poder tras una máscara feminista. Por otra parte, algunos puntos en común que hemos encontrado en todos los escraches tienen que ver con la manera en que fueron redactados: todos los escraches se escriben en primera persona, eso deja en claro que son expresiones personales, narrados desde la emoción y desde la vivencia personal de quien sufrió el abuso.

Los escraches se escriben totalmente desde la emocionalidad: ya sea desde el dolor profundo como desde la rabia y la indignación, ante la urgencia de expresar y compartir una situación. Es por ello que están cargados de adjetivaciones y expresividad narrativa. En ellos no solo se intenta dejar en claro lo que la víctima atravesó, sino también cómo se sintió al momento de vivir y sobrellevar los abusos/ violaciones/violencias.

Cabe aclarar que, generalmente, cuando se denuncia una situación de violencia de género en otros espacios las víctimas suelen ser revictimizadas. Estamos en el marco de una sociedad patriarcal en la que las mujeres y disidencias son siempre puestas en duda, cuestionadas, en la que sus discursos no se respetan y sus conductas reciben castigo (por ejemplo, cómo iban vestidas, a qué horas estaban caminando solas, sus prácticas sexuales, etcétera). Por ende, en la grupa FD la premisa inicial es que la víctima dice la verdad y que no se la cuestionará de manera machista ni patriarcal. Esta decisión colectiva y feminista repercute en la manera de escrachar puesto que genera confianza en quien narra la historia de que no será cuestionada ni revictimizada.

Otro de los puntos en común de los escraches es que el 80 \% de los escraches presentan el contexto de la relación o el espacio en el que se desataron los abusos o agresiones y relatan pormenores de los hechos. Indican fecha, lugar, detalles de cómo ha sucedido el o los hechos violentos. Se explicita cada marca que queda en la piel de quienes han sufrido la violencia machista. 
Asimismo, otro de los detalles que se brinda en los escraches es el nombre y apellido del violento. El 85 \% detalla identidad, brinda su foto, sus redes sociales y en algunos casos, también su teléfono y lugar de trabajo o ámbitos que frecuenta. Esto sirve para alertar a las demás mujeres y disidencias que pudieran conocerlo o que ya lo conocen y no saben de su comportamiento violento, acosador o abusivo.

Por otra parte, cabe aclarar que uno de los escraches fue destinado a un varón transgénero, con varios escraches por acoso y también a una psicóloga homofóbica. Además, se escracha a profesionales patriarcales y a comercios que ejercen algún tipo de violencia machista (bares, restaurantes, boliches, etcétera).

Como norma, en los escraches se utiliza el "lenguaje inclusivo". Esto es una política de FD: quien no utiliza lenguaje inclusivo (con la e o la x) no puede publicar en la grupa.

Podemos reconocer con claridad la necesidad de colectivizar el repudio, compartir la experiencia y el dolor, superar el miedo o la impotencia con el apoyo del sentir colectivo. Se hace evidente la necesidad de cuidar a otras mujeres, advertirles sobre ciertos varones peligrosos y animar a que otras puedan compartir sus experiencias.

También se ha generado una lista específica de músicos violentos, por ejemplo, pues es una de las áreas en las que los escraches son repetitivos. En esa lista figuran todos los varones escrachados, su perfil de Facebook y el porqué fueron escrachados.

El escrache es efectuado como un compromiso compartido que supone enfrentar a un sistema violento, machista y patriarcal que se expresa en el ámbito privado y desde la individualidad pero que es, ante todo, un problema social y por lo tanto colectivo.

El escrache virtual que circula en estos espacios cerrados, privados, destinados exclusivamente a feministas, remarca la importancia de la solidaridad y las redes de contención que se tejen entre mujeres a partir de los escraches. Frente a una sensación de desprotección y vulnerabilidad y lejos de un amparo institucional, se generan acciones en pos de poder colectivizar una demanda, compartir el dolor y proteger a otras de posibles agresiones. Dentro del grupo FD no se juzga a las compañeras ni se duda de lo que dicen, ello genera en las denunciantes un marco de contención especial que hace que se compartan momentos dolorosos con confianza. Estas acciones son una clara muestra de la sororidad entre mujeres, pero también de las estrategias de autodefensa y luchas feministas.

Como explicábamos antes, frente a los escraches jamás se pone en duda la palabra de la víctima. Esto tiene que ver con cortar los esquemas de la justicia patriarcal que revictimiza a las víctimas al momento de denunciar. Tampoco se desconfía de que haya sucedido lo que narran las personas que sufren alguna violencia machista. Al contrario, en algunos casos, quienes denuncian expresan sentir culpa y reconocen 
haber tenido reacciones violentas a las agresiones recibidas por parte del victimario. Nos remitimos a los comentarios surgidos a partir de los escraches, es claro el apoyo y la reiterada actitud de los miembros del grupo que buscan revertir la culpabilización de las víctimas e incentivarlas a que se fortalezcan y tomen medidas.

Los ejes con los que hemos trabajado nos hablan de ciertas realidades que enmarcan a los escraches. El primer eje con el que hemos trabajado tiene que ver con que los escraches se generan desde el dolor, el temor y la vergüenza. Esas tres son las emociones más recurrentes, sienten un miedo doble: al macho que las violentó y a las repercusiones del escrache (si se filtra fuera de FD y se expone que la víctima denunció). El dolor también es doble: al vivirlo y al revivirlo. Pero también se repite la idea de que las demás deben saber qué está pasando y alertar al resto de que cierta persona es violenta, para cuidarles. La emocionalidad puesta en juego es un elemento muy fuerte y con alto grado de potencia. Los relatos detallados muestran los sentimientos desgarradores por los que atraviesa la víctima al narrarlos.

El segundo eje es el del machismo reiterado. Gran parte de los escraches se hacen a varones que ya han sido escrachados dentro de FD o por mujeres que han hablado con otras a quienes también violentó el varón denunciado. Esto da aún más fuerza al relato, puesto que muestra que el varón tiene una conducta repetitivamente violenta.

Suele suceder además que una vez expuesto el escrache, con la descripción de la situación y la imagen del varón violento, comienzan los mensajes respondiendo al escrache. En esas respuestas, otras mujeres afirman que les ocurrieron situaciones similares con el mismo sujeto. A su vez, la exposición de ciertos varones violentos anima a otras a denunciarlos también. Afirman que, en el marco de FD, comparten el dolor y pierden el miedo.

El tercer eje nos habla de sororidad y es también muy recurrente. Gira en torno a la idea: "lo cuento para protegerte". Si se considera lo difícil que resulta para estas mujeres hablar sobre lo que sucedió, se entiende el por qué es necesario hacerlo, puesto que están en juegos las demás compañeras. Debido a intersecciones de clase, raza, nivel educativo y generacional, FD agrupa a feministas de ciertas características (mujeres jóvenes, universitarias, de clase media). Así las cosas, como el espacio geográfico que aglutina a FD es la ciudad de Córdoba, los varones escrachados son conocidos por varios de los miembros del grupo. Esto refuerza la demanda y el ejercicio de la sororidad: "te alerto sobre este varón que, además de ser violento, está muy cerca tuyo".

El último eje trabajado tiene que ver con los varones militantes de espacios progresistas. Las agrupaciones estudiantiles y partidarias han sido un foco constante de escrache en el marco de FD debido a que permiten la presencia de varones violentos. Estos se muestran progresistas discursivamente, de pensamiento de izquierda y afines al 
feminismo, pero en la práctica se comportan de manera violenta, patriarcal y misógina. Esto se denuncia una y otra vez en FD, no solo apela al escrache del sujeto en cuestión, sino también como una forma de interpelar a las compañeras militantes de estos varones que muchas veces encubren estas prácticas en el seno de las organizaciones sociales. A su vez, la importancia de denunciar a dichos hombres militantes radica en que estos frecuentan espacios de lucha feminista como movilizaciones y marchas.

\section{Machismos en la virtualidad, también}

Además del ciberacoso, Nuria Verges Bosch (2017) analiza que en el ciberespacio "los machismos persisten, a la vez que nuevos neo- machismos aparecen y se actualizan utilizando las nuevas tecnologías y las redes sociales como plataformas de actuación violenta privilegiadas y en auge". Además, la autora sugiere que el uso de las Tic puede facilitar y multiplicar exponencialmente los efectos de las violencias machistas, además de facilitar el anonimato y la suma de agresores; las redes sociales permiten la repetición, viralidad, difusión e, incluso, la normalización de estas violencias (2017, p. 5).

Los machistas también son muy activos en las redes sociales, aunque no siempre sus actuaciones son tan extremas, sus comentarios y argumentos sirven de base, justifican e incluso, animan demasiadas agresiones a mujeres y también a personas del colectivo LGTTBOI y otros colectivos minorizados: "No hay más que ver algunos de los comentarios que aparecen ante noticias sobre mujeres asesinadas por sus parejas o ex parejas que defienden el agresor y culpabilizan a la víctima" (Verger Bosch, 2017).

Lo que surge en la era digital son lo que Verger Bosch llama neo machismos:

Los neo machismos son un fenómeno reaccionario. En este sentido, aparecen como reacción a los logros feministas de las últimas décadas, sobre todo, ante la posibilidad de perder los privilegios que antaño el machismo les había otorgado por el simple hecho de haber nacido hombres cis y comportarse de acuerdo a [sic] la masculinidad hegemónica y heteronormativa. (2017, p. 54)

Cabe aclarar que se caracterizan por cuestionar los recientes avances en materia de género y las legislaciones conseguidas, pero también por atacar ferozmente -a menudo en forma de machitrolls ${ }^{5}$ - a las feministas, incluso crearon un nuevo concepto para llamarlas feminazis (Verger Bosch, 2017).

A pesar de los embates del patriarcado, las mujeres cada vez más tomamos las redes sociales y el espacio de la virtualidad. Generamos contenidos, intercambiamos información, bienes y servicios. Construimos colectivamente estrategias de defensa y resistencia. Sin embargo, sigue siendo necesario y urgente generar una mirada crítica y profunda con respecto a las brechas digitales con perspectiva de género.

Los machitrolls suelen tener varios perfiles falsos en Facebook (alguno incluso de mujer), sin foto o con fotos falsas, con la intención de acosar en páginas feministas impunemente. 
En este marco, FD creó sus propias reglas de ingreso/egreso e inclusión/exclusión del espacio virtual. Así también, generaron herramientas para detectar quiénes son feministas o al menos, son potenciales feministas.

Para aceptar a alguien en la grupa [sic], las administradoras revisamos el perfil. Vemos que tengas publicaciones feministas. Si no tenés publicaciones feministas se nos hace difícil aceptarte. Pero, ponele, no tenés publicaciones feministas pero tenés publicaciones anti Macri, bueno... sí. No hay un criterio fijo de inclusión, pero sí de exclusión. Si vos no estás ni cerca de las luchas del feminismo: o sea, que no estás a favor de las luchas mapuches en contra de Macri, a favor del salario digno... o sea, si tenés un perfil de una persona que apoya a los movimientos a favor de los derechos y las igualdades sociales, entonces que venga, estás de este lado. (Comunicación personal, administradora del grupo FD, mayo de 2018)

Por tanto, de esta manera se aseguran ciertos requisitos indispensables: ser feministas, contrarias al gobierno neoliberal actual en Argentina y a los gobiernos neoliberales en general, defensora de los derechos humanos y sus luchas, y ser antiracista. No obstante, si bien el grupo intenta incluir a todas las mujeres y diversidades feministas, son conscientes de que existe una limitación de participación marcada por intersecciones como clase social o nivel de estudio. De esta manera, se plantean debates y reflexiones dentro del FD que difícilmente pueden ser comentados o comprendidos por miembros no universitarios. Lo que termina sucediendo es que el acceso al grupo se encuentra sectorizado, también los escraches. Son ciertos varones los escrachados: blancos, de clase media, universitarios, vinculados a grupos y espacios progresistas de militancia, docentes universitarios, etcétera.

En lo que respecta a los criterios de exclusión del grupo, queda claro que no pueden formar parte los varones cis: "Varones cis están excluidos y que vayan a llorar al campito. Se pueden ir a deconstruir con los pibes" (Comunicación personal, administradora del grupo FD, junio 2018). Esto nos muestra criterios de demarcación de ingreso y participación en el grupo con el fin de asegurar que sea un espacio protegido de posibles violencias machistas y en el cual la centralidad del diálogo incluya necesariamente argumentos y debates desde una perspectiva feminista.

De esta forma intentan asegurar, no solo la participación de personas feministas, sino también la no participación de varones cisgénero y la vigilancia que se gestiona tiene que ver con evitar acosos, machismos y la aparición de los machitrolls. Bajo estos parámetros claros se condicionan las participaciones y se protege la enunciación de escraches feministas.

\section{Conclusiones}

La virtualidad es otro ámbito en el que el patriarcado todavía efectúa gran dominio. Sin embargo, los feminismos caminan a la par de los avances tecnológicos y habitan la 
porosidad de la tecnología para interceder en el poder. Construyen herramientas virtuales de resistencia y lucha que se traducen luego al mundo analógico. El movimiento feminista ha generado acciones y discursos performativos que repolitizan la ciencia y la técnica.

El escrache permite nuevas maneras de protestar, novedosas formas de decir, pero también incorpora otros límites a lo decible. Eso que se mantenía en silencio o se hablaba en una jefatura policial empieza a tomar otros espacios y diferentes posibilidades. El escrache desafía a las otras violencias más micro: las normas que marcaban lo decible y lo indecible en una sociedad y lo aceptable e inaceptable. Además, desafía al miedo, al temor, a la culpa y permite la liberación: las víctimas se expresan y en ese decir encuentran la posibilidad de recuperar su poder, el poder entendido en términos colectivos y no individuales exclusivamente.

Al decir y ser apoyadas por otras, las mujeres cobran fuerza, recuperan la dignidad y logran encauzar el enojo hacia el victimario, sobre todo en una sociedad en la que las instituciones no solo no acompañan a las víctimas, sino que las revictimizan y las exponen a los dictámenes de una justicia patriarcal, igualmente patriarcal que el sistema contra el que luchan. Es una especie de acción colectiva que se concreta a partir del escrache individual virtual, pues repercute en otras y se alimenta un discurso capaz de gestionar rechazos sociales al machismo y sus representantes.

El escrache pone elementos de la vida privada en el espacio público y en el caso analizado de FD, se trata de un espacio público virtual compartido por personas con características en común: cordobesas, feministas, comprometidas con las víctimas de la violencia de género.

Por otra parte, el escrache surge y surte efecto en el marco de un Estado que no se responsabiliza por las víctimas de las violencias de género. Un Estado ausente frente a los abusos de la justicia patriarcal, el cual da un mensaje de impunidad para los violentos cuando no interviene, por eso decimos también que el Estado es responsable puesto que omite o no concreta políticas públicas con perspectiva de género, incluso encubre a los violentos.

Tal como señala Francesca Gargallo, la violencia machista es preocupante: según una investigación realizada en doce países de América por la Organización Panamericana de la Salud/ Organización Mundial de la Salud (OPS/OMS), en colaboración con los Centros para el Control y Prevención de Enfermedades de los Estados Unidos (CDC),

[...] todas las entidades que no pueden ser consideradas ni mínimamente feministas, entre el 17 y el 53 \% de las mujeres entrevistadas (i 180.000 !) han reportado haber sufrido o sufrir violencia o abuso por ser mujeres. Sin embargo, el 64 \% de ellas no buscó ayuda ni denunció porque la transgresión de los derechos humanos implícita en la violencia contra las mujeres no se registra como tal ni siquiera por las víctimas. (Gargallo, 2013) 
La violencia machista avanza y el Estado continúa sin responder a la altura de la circunstancia de esta problemática urgente. La virtualidad se convierte en un territorio de disputas en el cual las feministas exploran las posibilidades que ofrecen las tecnologías de la comunicación y la información para la lucha contra la violencia de género. Así, las mujeres como sujetos políticos buscan sus propios métodos de acción para poder ingresar de lleno en un camino que apunte a desandar y deshacer los machismos y sus violencias.

\section{Referencias}

Arendt, H. (1993). La condición humana. Paidós.

Belloch C. (2007). Las tecnologías de la información y comunicación (TIC) (Material docente en línea). Departamento de Métodos de Investigación y Diagnóstico en Educación. Universidad de Valencia. http://www.uv.es/bellochc/pedagogia/EVA1.pdf

Bonavitta, P., y de Garay, J., (2014, julio-septiembre). Género, violencia e Internet: el caso de México y Argentina. Revista Question, 1(43). https://perio.unlp.edu.ar/ojs/index.php/question/ article/view/2188/1966

Bonavitta, P., De Garay J., y Camacho J., (2015, octubre-diciembre). Mujeres, feminismos y redes sociales, acceso, censura y potenciación, Revista Question, 1(48). https://perio.unlp.edu.ar/ojs/index. php/question/article/view/2740

Bonder G., (2010, septiembre-octubre). Juventud, Género y TIC: Imaginarios en la construcción de la Sociedad de la Información en América Latina. ARBOR Ciencia, Pensamiento y Cultura, CLXXXIV(733), 917-934. https://doi.org/10.3989/arbor.2008.i733.234

Castel R., (1995). La metamorfosis de la cuestión social. Fayard.

Castells M. (1996). La era de la información. Economía, sociedad y cultura (pp. 285-316). México Siglo XXI.

Castells, M. (2001). The Internet Galaxy: reflections on the Internet, Business and Society. University Press.

Cepal (2013). La industria del software y los servicios informáticos: un sector de oportunidad para la autonomía de las mujeres latinoamericanas. Naciones Unidas. https://repositorio.cepal.org/bitstream/ handle/11362/36857/1/S1420253_es.pdf

Díaz C., y Navarro P. (1998). Análisis de contenido. En Métodos y técnicas cualitativas de investigación en ciencias sociales (pp. 203-206). Síntesis.

García Manso, A. (2007). Cyborgs, mujeres y debates. el ciberfeminismo como teoría crítica. Barataria. Revista Castellano-Manchega de Ciencias Sociales, (8), 13-26. https://doi.org/10.20932/ barataria.v0i8.202

Gargallo, F. (2013, marzo 7). Dudas y prácticas autónomas feministas ante las políticas públicas y las garantías de buena vida para las mujeres. En Foro Políticas de Igualdad de Género en México: avances e insuficiencias. Maestría en Estudios de la Mujer, Universidad Autónoma Metropolitana (UAM-Xochimilco). 
Haraway, D. (1984). Ciencia, cyborgs y mujeres. La reinvención de la naturaleza. Cátedra.

Jeong, S. (2015, octubre 27). The internet of Garbage (Conferencia audiovisual). The Berkman Klein Center for Internet $\mathcal{E}$ Society. https://www.youtube.com/watch?v=pUSctMLLNUE

ONU. (2018, 20 de noviembre). Artículo 11: presunción de inocencia y crímenes internacionales. Noticias ONU. https://news.un.org/es/story/2018/11/1446621

Padilla, M., y Mezquita, R. (2006). Penélope: tejiendo y destejiendo la red. En Reunión de Ovejas Electrónicas (ROE) (2006), Ciberactivismo, Sobre usos políticos y sociales de la Red. Virus.

Pérez-Foguet. A. (ed.) (2006). Tecnologías de la información y las comunicaciones para el desarrollo. Tecnologías de desarrollo humano y acceso a servicios básicos. Ingeniería Aplicada a la Cooperación para el Desarrollo, Volumen 5. Associació Catalana d'Enginyeria Sense Fronteras. https:// upcommons.upc.edu/bitstream/handle/2 11 17/25169/M5_Tecnolog\%C3\%ADas\%20de\%20 la\%20informaci\%C3\%B3n\%20y\%20las\%20comunicaciones\%20para\%20el\%20desarrollo. pdf? sequence $=6$ EisAllowed $=\mathrm{y}$

Postman, N. (1991). Divertirse hasta morir: Discurso público en la era del espectáculo. Ediciones de la Tempestad.

Sánchez Kuri, L. (2016). Del escrache feminista como acción sororaria y su comunicación efectiva para la denuncia. Mujeres.net. http://www.mujeresnet.info/2016/06/del-escrache-feministacomo-accion-sororaria-y-su-comunicacion-efectiva-para-la-denuncia.html

Segato, R. (2008). La guerra contra las mujeres. Traficante de sueños.

Vega Montiel, A., (2010, enero-abril). Las mujeres y el derecho humano a la comunicación: su acceso y participación en la industria mediática Revista Mexicana de Ciencias Políticas y Sociales, LII(208), 81-95. http://www.redalyc.org/articulo.oa?id=421 16044005

Vergés Bosch, N. (2017). Redes sociales en perspectiva de género: Guía para conocer y contrarrestrar las violencias de género on-line. Instituto Andaluz de Administración Pública. https://donestech.net/ files/redessociales.pdf

Wilding, F. (1998). Notes on the Political Condition of Cyberfeminism. Art Journal, 57(2), 7-70. https://doi.org/10.1080/00043249.1998.10791878

Zafra, R. (2015). Netianas, N(h) hacer mujer en Internet. Lengua de Trapo.

Zani, A. (2017). Retórica del escrache: entrega I. La Primera Piedra. https://www.laprimerapiedra. com.ar/2017/10/retorica-del-escrache-entrega-i/ 